\title{
Niccolò da Corte, escultor de portadas y fuentes en Génova y Granada
}

\author{
Niccolò da Corte, sculptor of façades and fountains in Genoa and \\ Granada
}

Nuria MARTÍNEZ JIMÉNEZ

Universidad de Granada

ORCID: http://orcid.org/0000-0003-2479-7598 / nuriamj@correo.ugr.es

DOI: http://dx.doi.org/10.18002/da.v0i19.6242

Recibido: 15-IV-2020

Aceptado: 12-VI-2020

RESUMEN: Este artículo reflexiona sobre la labor de Niccolò da Corte como escultor de portadas de palacios reales y nobiliarios y, sobre todo, como escultor de fuentes, labor por la que fue reconocido tanto en el norte de Italia como en España.

Palabras clave: Niccolò da Corte; escultura; Mantua; Génova; Palacio de Carlos V; siglo XVI.

ABSTRACT: This article reflects on the work of Niccolò da Corte as a sculptor of covers of royal and noble palaces and, above all, as a sculptor of sources, work for which he was recognized in both northern Italy and Spain.

Keywords: Niccolò da Corte; sculpture; Mantua; Genoa; Palace of Charles V; sixteenth century.

Niccolò nació antes de 1507 en Cima da Porlezza (provincia de Como) ${ }^{1}$. Igual que otros artistas, el joven debió dar sus primeras cinceladas en el taller de su padre Francesco da Corte. Pronto se trasladó a Milán para integrarse en el taller de Agostino Busti, más conocido como "Bambaia". Motivado, posiblemente por la compleja situación de Milán, en 1522 se trasladó a Génova donde trabajaba Antonio Maria Aprile², y pronto

\footnotetext{
${ }^{1}$ Margarita Estella y Federica Lamera, "Niccolò da Corte", en Dizionario Biografico degli Italiani, vol.31, 1985, http://www.treccani.it/enciclopedia/niccolo-da-corte_\%28Dizionario-Biografico\%29/.

${ }^{2}$ Federico Alizeri, Notizie dei professori del disegno in Liguria dalle origini al sec. XVI, V (Genova: Luigi Sambo-
}

adquirió un local junto al Puente dei Cattanei $^{3}$. Sin embargo, en torno a 1524 se trasladó a Padua donde se integró en el taller de Giammaria Mosca "el paduano". Con él realizó su primera obra conocida: un conjunto de siete figuras de terracota de talla completa y dos de media, que formarían parte de una Lamentación destinada a la capilla de San Bartolomeo en El Carmen ${ }^{4}$.

lino tip., 1877), 145.

${ }^{3}$ Yasmine Helfer, "Gugliermo della Porta dal Duomo di Genova al Duomo di Milano", Prospettiva, Rivista di storia dell'arte antica e moderna, n¹32 (2008), 62.

${ }^{4}$ Markham Schulz, Giammaria Mosca Calle Padovano, A Renaissance Sculptor in Italy and Poland (Pensylvania: 


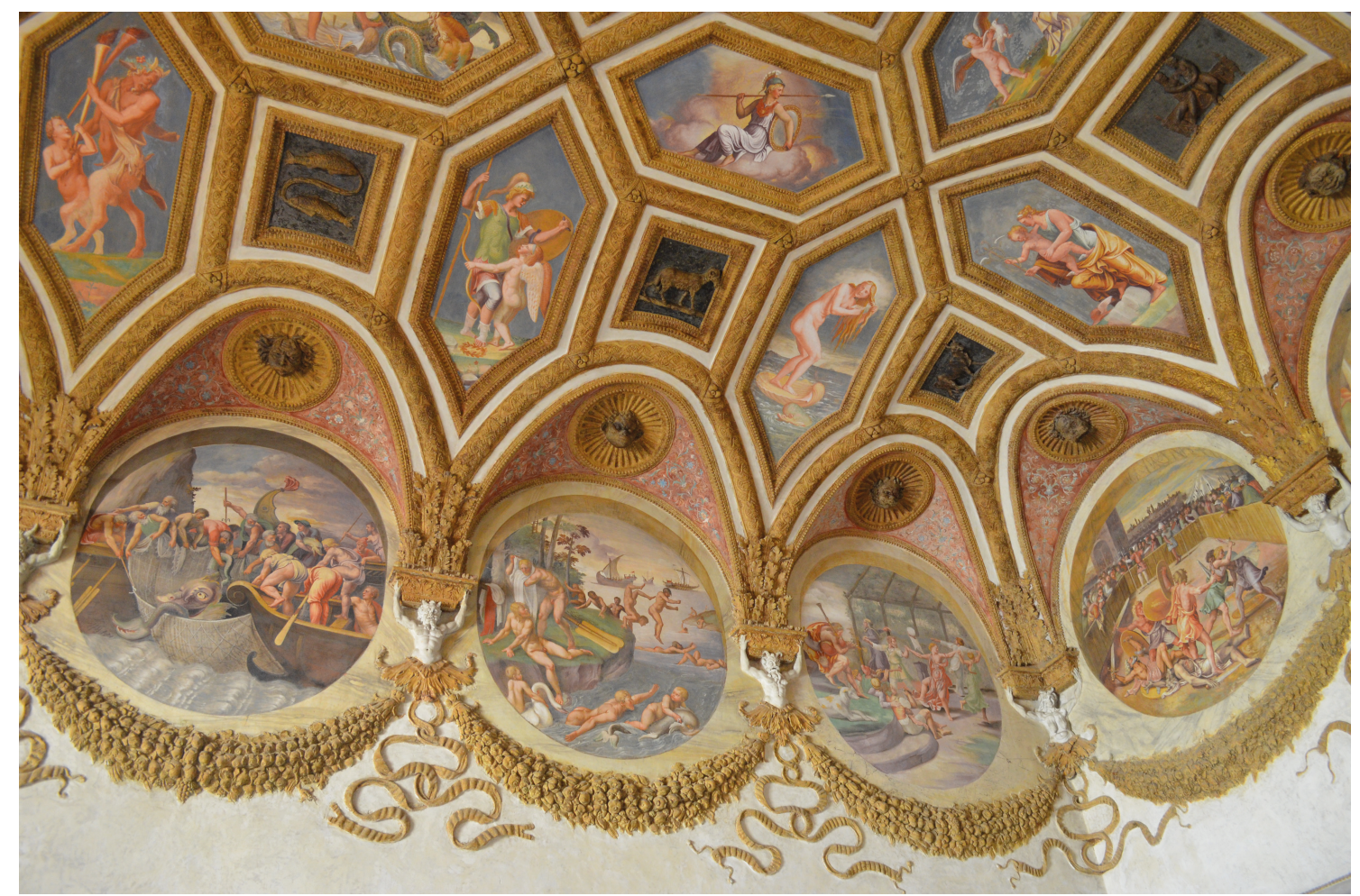

- Fig. 1. Sala de los Vientos. 1527. Palacio del Té. Mantua. Fotografía de la autora.

Acorde con Yasmine Helfer pensamos que al menos entre 1527 y 1528 Niccolò trabajó en Mantua con el sobrenombre "Niccolò da Milano" ${ }^{\prime 5}$. Partiendo de las referencias obtenidas de la documentación sabemos que Niccolo "scultori -schultore da milano-" trabajó entre el 5 de octubre de $1527^{6}$ y el 24 de marzo de 1528 en el Palacio del Té de Mantua ${ }^{7}$. La primera intervención tuvo lugar en la sala de los Vientos, llamada así por los dieciséis vientos de color bronce que soplan desde el mundo sublunar (Fig. 1). Acorde con otras estancias del palacio, en el ornato se combinó el intenso colorido de las pinturas con el volumen de los estucos, para crear

State Universiti Press, 1998), 29-30.

${ }^{5}$ Helfer, “Gugliermo della Porta...", 75.

${ }^{6}$ Daniela Ferrari, Giulio Romano. Repertorio di fonti documentarie (Mantova: Publicazioni degli archivi di Stato. Fonti XIV. Ministero per i beniculturali e ambientali. Ufficio centrale per i beni archivistici, 1992), 240 $-261$.

${ }^{7}$ Archivio di Stato di Mantova (ASMn), Pittori per gli anni 1279-1706, Schede- Davari, c. 1, f. 673r. un espacio celestial con divinidades como Neptuno, en el que los signos zodiacales se vinculan a las actividades humanas, a través de los vientos ${ }^{8}$. En la decoración participaron los pintores Agostino Mozzanega y Benedetto Pagni y los estucadores Andrea de Conti y Niccolò da Milano' ${ }^{9}$, cuyas primeras intervenciones consistieron en la ejecución de las figuras de los vientos. De forma prácticamente paralela a la decoración pictórica de los tondos, Niccolò comenzó a realizar los estucos del resto de la estancia. Para ello, entre el 5 octubre y el 11 de enero de 1527, ejecutó los dieciséis torsos de monstruos y los follajes que rodean los tondos, el marco tallado y la rica cenefa de arpías que bordea toda la estancia. Además, hizo los festones y las cintas ${ }^{10}$. Como resultado, se creó un original conjunto que maravilló al propio em-

\footnotetext{
${ }^{8}$ Rodolfo Signorini, Il Palazzo del Te e la camera de Psique (Mantova: Sometti, 2001), 27.

${ }^{9}$ Paolo Carpeggiani y Chiara Tellini, Giulio Romano a Mantova (Mantova: Sintesi, 1987), 85.

${ }^{10}$ Ferrari, Giulio Romano..., 255, 261.
} 


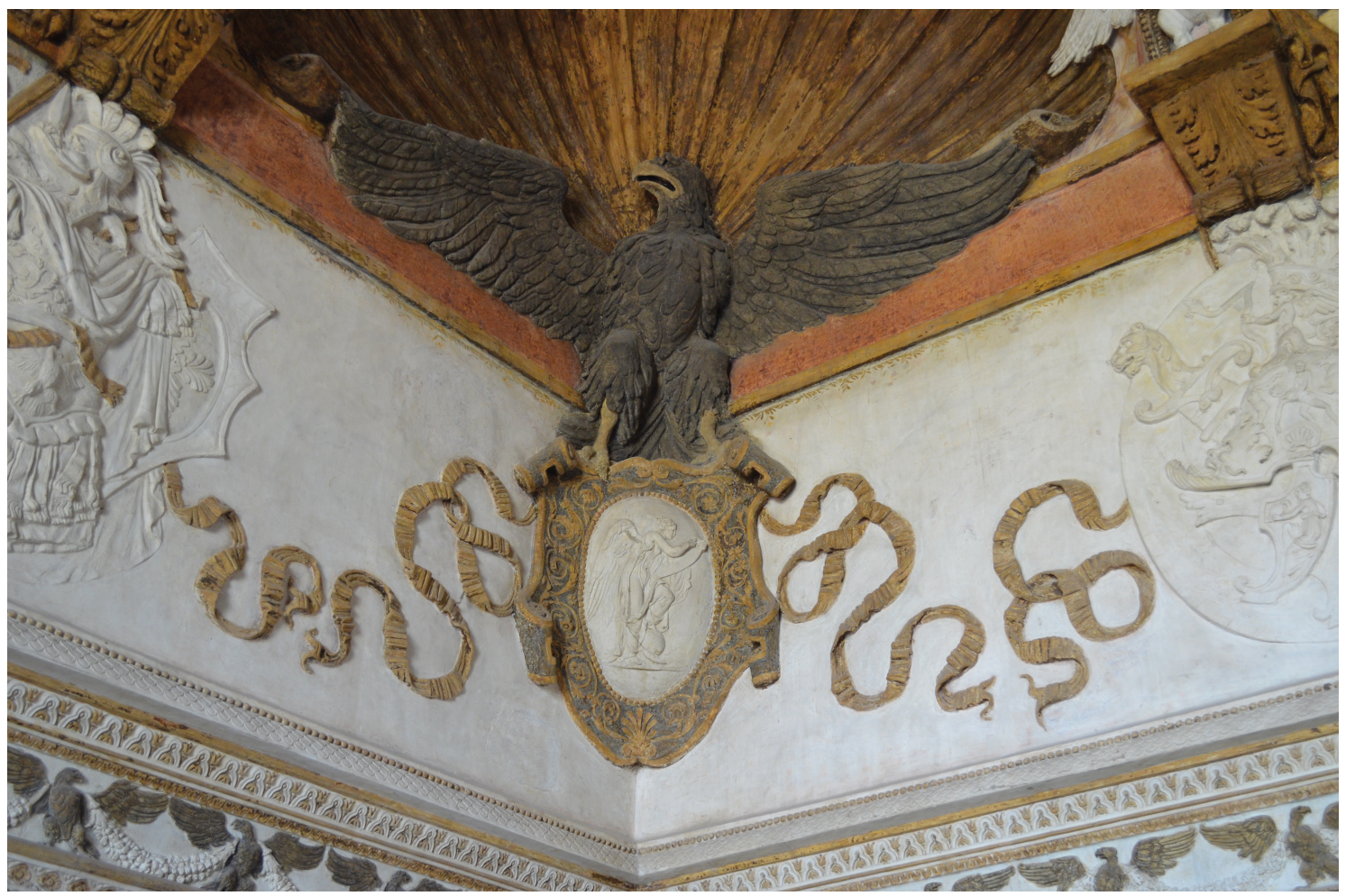

- Fig. 2. Sala de las Águilas. 1527-1528. Palacio del Té. Mantua. Fotografía de la autora.

perador durante la estancia en la ciudad en $1530^{11}$.

Niccolò también trabajó junto con Primatriccio y Agostino da Mozzanega en la sala de las Águilas ${ }^{12}$. Entre el 1 de diciembre de 1527 y el 20 de febrero del año siguiente, el artista dio forma a cuatro de las termini o hermas ubicadas entre las composiciones pictóricas, un trofeo y dos camafeos, donde se diferencia la figura de la Fama escribiendo que remite al grabado de Agostino Veneziano. Además, realizó "cuatro partes de estuco para adornar los cuatro frisos"13 (Fig. 2). Pensamos que estas "partes de estuco" corresponderían con los bajorrelieves de panoplias militares, cuya sutileza en ciertas ocasiones, manifiesta el dominio del schiacciato. Un mo-

${ }^{11}$ Giulio Romano, Cronaca del Soggiorno di Carlo V in Italia (dal 26 Luglio 1529 al 25 Aprile 1530). Documento di Storia Italiana estratto da un códice della Regia Biblioteca Universitaria di Pavia (Milán: Ulrico Hoepli, 1893), 266.

\footnotetext{
${ }^{12}$ Carpeggiani y Tellini, Giulio Romano..., 86-87.

${ }^{13}$ Ferrari, Giulio Romano..., 255.
}

tivo decorativo frecuente en la decoración de frisos y candelieri, que Niccolò convirtió en una pieza clave en el ornato de los pedestales de las portadas de los palacios.

Los trabajos de Niccolò en la sala de los Candelabros se concentraron en la ejecución de siete tondos de estuco entre los que se identifica la escena de Leda y el Cisne. Además hizo dos de los trofeos representados en las esquinas y cinco de los candelabros que limitan los cuadros pintados. Finalmente, cabe destacar la intervención del artista en la sala de las Victorias donde, entre el 1 de diciembre y el 20 de febrero de 1528, Niccolò realizó cuatro cabezas que formarían parte del ornato y dos de las figuras que dan nombre a la habitación ${ }^{14}$. 
NICCOLÒ DA CORTE, ESCULTOR DE PORTADAS Y FUENTES EN GÉNOVA

Como recoge García Cueto, hasta el establecimiento de Andrea Doria "Génova permaneció ajena a las dinámicas renacentistas de mecenazgo"15. En este sentido, la culminación de la intervención en el palacio del Té en 1528 brindó a Niccolò una extraordinaria oportunidad para tornar a Génova e integrarse en el nuevo contexto genovés.

La primera obra conocida es la portada del palacio de Andrea Doria en la plaza de San Mateo (Fig. 3). La decoración de la puerta debió realizarse entre 1528 y 1529, es decir, entre la donación del palacio a Andrea Doria el 7 de octubre de 1528 (como reconocimiento a los servicios a la República) y el traslado del artista a Savona, donde se localizaba el 19 de febrero de $1529^{16}$. La puerta responde a la tipología habitual de los palacios genoveses construidos o reformados en la década de los veinte. La novedad radica en el empleo de elementos decorativos que remiten a la Antigüedad clásica. Como ya señaló Rosenthal ${ }^{17}$, la principal innovación se encuentra en el cuerpo superior. Aquí siguiendo los modelos de Mantegna en la Cámara de los Esposos en el Palacio Ducal de Mantua o de la decoración de la fachada de la iglesia San Sebastían de Alberti, Niccóló colocó una pareja de ángeles portando escudos y sosteniendo una cartela con una inscripción en latín: SENAT; CONS; ANDREAE

${ }^{15}$ David García Cueto, "Aproximación al mecenazgo de la comunidad genovesa en el Reino de Granada durante los siglos XVI y XVII", en Génova y la Monarquía Hispánica (1528-1713), coord. por Manuel Herrero Sánchez, Yasmina Rocío Ben Yessef Garfia, Carlo Bitossi y Dino Puncuh (Génova: Società Ligure di Storia Patria, 2011), 705. Para profundizar sobre el mecenazgo de Doria, véase: Pietro Boccardo, Andrea Doria e le arti (Roma: Palombi, 1989).

${ }^{16}$ Marco Campigli, "Silvio Cosini, Niccolò da Corte e la scultura a Palazzo Doria", Nuovi Studi, Rivista di arte antia e moderna, no 20 (2014), 88.

${ }^{17}$ Earl Rosenthal, Niccolò da Corte and the portal of the palace of Andrea Doria in Genoa (Berlin: Walter de Gruyter \& co, 1968), 361.

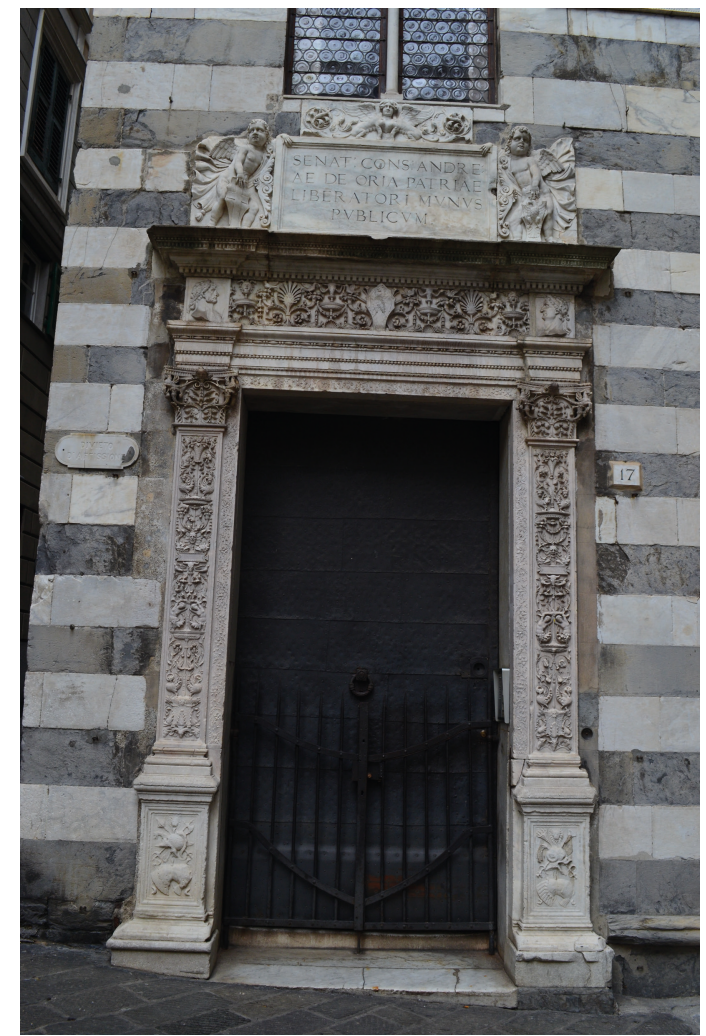

- Fig. 3. Puerta del Palacio Doria. 1528. Plaza de San Mateo. Génova. Fotografía de la autora.

DE ORIA PATRIAE LIBERATORI MVNVS PVBLICVM. Otra singularidad, es el uso de candelieri en las pilastras. Cómo indicamos, Niccolò había realizado cinco candelabros en la sala homónima del palacio del Té, por lo que ya tenía experiencia en este tipo de decoraciones. Sin embargo, en esta ocasión demostró una mayor precisión a la hora de elaborar sugestivos conjuntos entre las que se halla un rostro similar al retrato de Mantegna en la Cámara de los Esposos del palacio Ducal de Mantua. Por último, conviene destacar el novedoso ornato de los pedestales con cascos y escudos militares; motivo ornamental que caracterizará las portadas de Niccolò y que tuvo una enorme difusión.

Concluida la puerta del palacio Doria, Da Corte se trasladó a Savona donde el 13 de octubre de 1529 aceptó el encargo de un grupo de quince estatuas de la Pasión en terracota para la iglesia de Santa Maria di 
Castello $^{18}$, que debían de ser al menos de la misma calidad de las de San Giovanni de Génova. Teniendo en cuenta, que la capilla de San Giovanni de la catedral aún no había sido realizada, esta referencia aludiría al relieve del Bautismo de Cristo de la iglesia de San Giovanni il Vecchio de Génova ${ }^{19}$. Más allá de la relevancia del grupo escultórico, el encargo más sobresaliente fue la fuente para Gregorio da Cesarea, junto con Pace Antonio Sormano, fundador de un notable taller especializado en la decoración de interiores, esculturas y fuentes ${ }^{20}$. En la actualidad, no hay constancia de la ubicación de la fuente de Cesarea; sin embargo, nos encontramos ante una obra especialmente relevante puesto que constituye la primera referencia de Niccolò como escultor de fuentes.

De vuelta a Génova, Da Corte se integró en el taller de Perino del Vaga en el palacio Doria en Fassolo. Partiendo de su experiencia como escultor de portadas, su primera obra consistió en la realización de la puerta datada en $1529^{21}$, que hoy constituye el acceso principal (Fig. 4). Si bien es cierto que en la obra de la plaza de San Mateo, Niccolò había introducido ciertas novedades, esta portada tiene un carácter plenamente romano. En ella, da Corte, no sólo debió de realizar dos imponentes columnas dóricas, sino encargarse del adorno escultórico como el escudo que corona la portada, armaduras dispuestas sobre el frontón, o los relieves de las figuras de la Fama que sostienen una corona de laurel mientras tocan la trompeta.

${ }^{18}$ Rosenthal, Niccolò da Corte..., 363.

${ }^{19}$ Estella y Lamera, "Niccolò da Corte".

20 Ernesto Baldassarre y Renato Bruno, Schedario degli uomini illustri in Savona (Savona: A Campanassa, 1981), 233. Elena Parma Armani, Il secolo d'oro dei genovesi: il Cinquecento, en La scultura a Genova e in Liguria dalle origini al cinquecento (Génova: Cassa di Risparmio di Genova e Imperia, 1987), 269.

${ }^{21}$ Según Rosenthal, da Corte debió seguir los modelos de Perino y de Silvio Cosini. Rosenthal, Niccolò da Corte..., 359. Sin embargo, la puerta está fechada en 1529 y la llegada del artista pisano a Génova se documenta a partir de 1530, por tanto Niccolò debió de trabajar bajo la supervisión directa del maestro florentino.

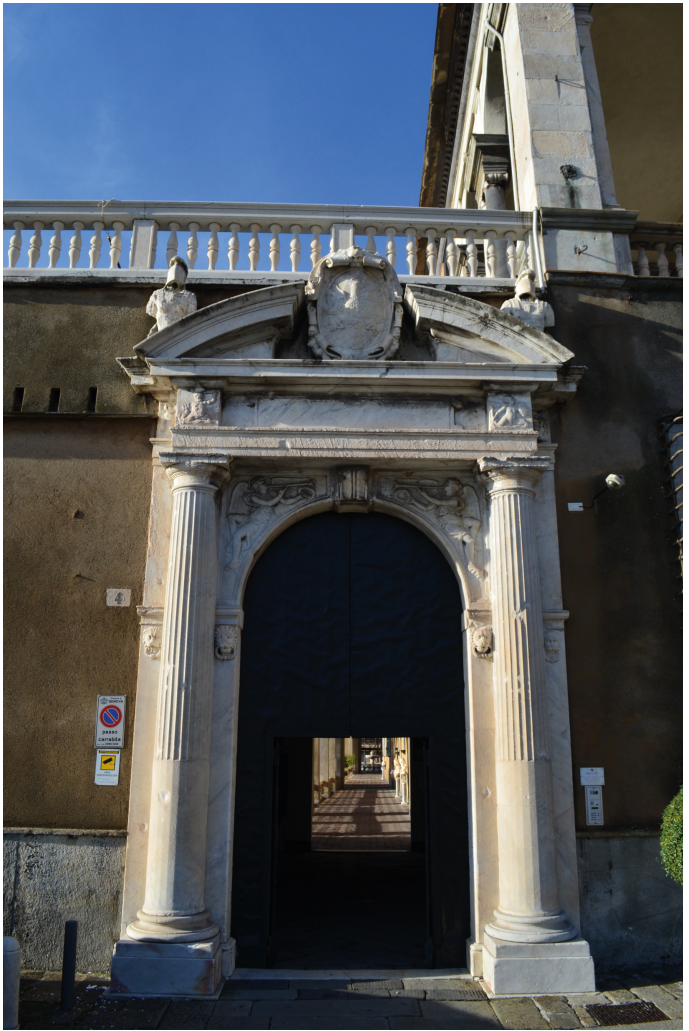

- Fig. 4. Puerta de acceso al Palacio Doria. c. 1529. Génova. Fotografía de la autora.

También, sobresalen los tritones del friso y los cuatro leones labrados en mármol que portan argollas.

A pesar de la notable actividad de Niccolò en el palacio Doria, la estancia de Silvio Cosini en Génova entre 1530 y el verano de $1532^{22}$, constituyó un punto de inflexión en la decoración del palacio. El hecho de ser el único escultor recogido por Vasari, ha conducido a numerosos historiadores a atribuir al artista pisano la ejecución de la mayor parte de las obras escultóricas: portales, chimeneas o fuentes. Sin embargo, pensamos que Cosini pudo contar con algunos colaboradores como Da Corte. Es el caso de la portada de la actual calle San Benedetto, en la que es posible identificar la mano de Silvio $^{23}$ en

\footnotetext{
${ }^{22}$ Campigli, "Silvio Cosini ...", 83-84. En su artículo el autor también planteó la posibilidad de que Niccolò realizara las chimeneas. Campigli, "Silvio Cosini...", 90.

${ }^{23}$ Giorgio Vasari, Le vite dei più eccellenti pittori, scultori e architetti (Roma: Newton Comton, 2012), 901.
} 
las figuras femeninas y la de Niccolò, quien empleó su característica técnica del schiacciato para representar las armas en los pedestales (Fig. 5). Tampoco sería de extrañar la participación de Niccolò en la Fuente de los Delfines (Fig. 6). Esta fuente es el único elemento decorativo que queda del jardín sur diseñado por Perino del Vaga y se caracteriza por una estructura de pilas superpuestas, ornamentadas por figuras de grifos, tritones, putti y delfines. Efectivamente, la delicada factura de la fuente se corresponde con el cincel de Cosini. Sin embargo, la similitud entre los rostros de las águilas de la base con las argollas del palacio de Carlos V, así como de los mascarones y los putti con las figuras del Pilar de Carlos V, nos invitan a pensar en la colaboración del artista lombardo. Además, esta intervención sería clave en el desarrollo de su carrera, no sólo porque le otorgaría cierta fama como escultor de fuentes y jardines, sino porque le permitió conocer de primera mano el modo de trabajar de los artistas florentinos, grandes especialistas en la ejecución de fuentes.

Fuera del palacio Doria, Caldelari identificó a "Niccolò Corti da Corte" en la documentación de las obras de la Catedral de Lugano $^{24}$. Su intervención tuvo lugar en 1530 y se centró en la ejecución de los tondos con altos relieves de Santos que se localizan en el arquitrabe de la fachada. No obstante, el principal encargo consistió en la realización del Baldaquino de San Giovanni para la catedral de Génova, por lo que en 1531 estableció una compañía con Gian Giacomo della Porta, que se mantuvo activa hasta la culminación del monumento sepulcral de Giuliano Cibo en $1537^{25}$.

${ }^{24}$ Lara Calderari, “Le trasformazioni tra Quattro e Cinquecento. Necessità manutentive e ambizioni identitarie", Arte e cultura, no 6/7 (2017), 123.

${ }^{25}$ Margarita Estella, “La importación de esculturas italianas. Obras en España del taller de los Della Porta, de Giambologna y del Naccherio", en El modelo italiano en las artes plásticas de la Península Ibérica durante el Renacimiento, coord. por María José Redondo Cantera (Valladolid: Universidad de Valladolid, 2004, 428

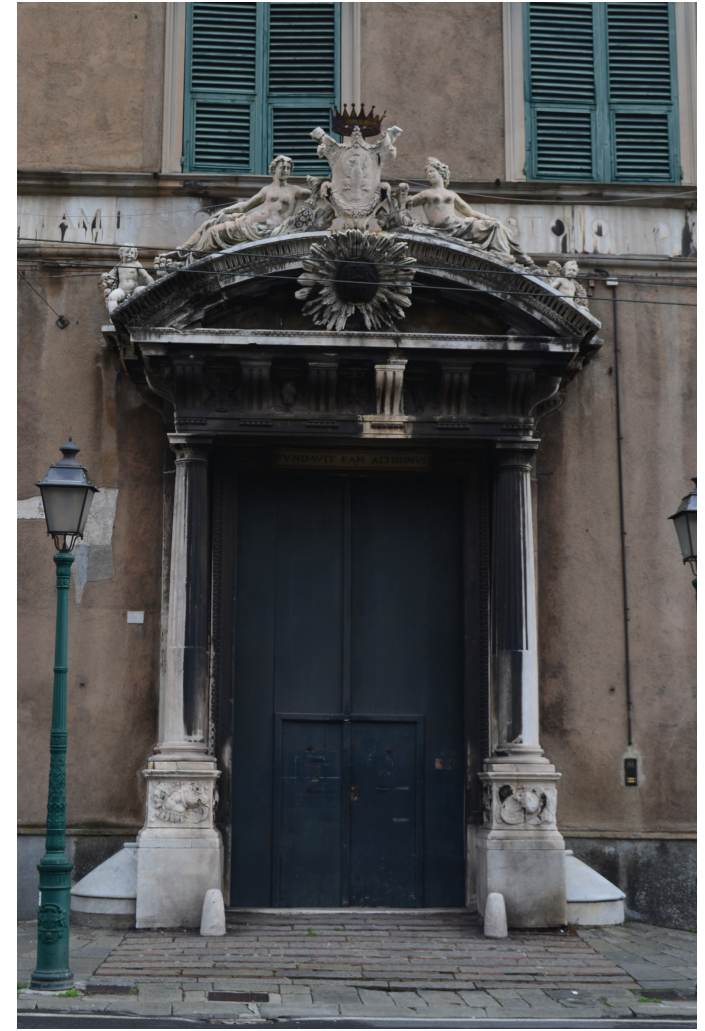

- Fig. 5. Puerta del Palacio Doria hacia la calle San Bernardo. c. 1530-1532. Génova. Fotografía de la autora.

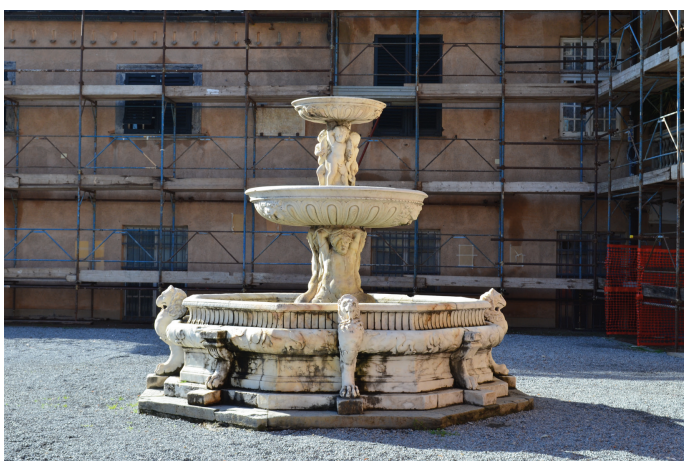

- Fig. 6. Fuente de los Delfines. Palacio Doria. c. 1530-1532. Génova. Fotografía de la autora.

Tras el éxito de los jardines de la villa Doria, las familias genovesas comenzaron a introducir espacios verdes en sus palacios. Es el caso del paradigmático jardín de Martín Centurione, ubicado en la cuesta de San Francisco en Génova, en el que, entre 1531 y 1534 se incorporaron galerías, escaleras, cornisas y fuentes realizadas por Matteo da Carona. Poco tiempo después del inicio de 
esta obra, Adamo Centurione (uno de los banqueros genoveses predilectos del Emperador) intervino como intermediario para la contratación de una serie de piezas para la renovación de los jardines del Real Alcázar de Sevilla ${ }^{26}$. Como indicó Redondo Cantera, tras el paso de Carlos V e Isabel de Portugal el gusto por el arte renacentista se impuso en Sevilla en fuerte contradicción al arte morisco. En este contexto, en 1532 se emprendieron una serie de reformas encaminadas a renovar el Patio de las Doncellas ${ }^{27}$. Para ello, el 12 de diciembre Antonio Maria Aprile, Niccolò da Corte, Gian Giacomo della Porta, y Antonio Novo di Lanzia se comprometieron a hacer las pilastras y las columnas del patio inferior y del corredor superior ${ }^{28}$. Sin embargo, el contrato no se cumplió, por lo que entre 1534 y 1535 volvieron a concertar las piezas que llegaron a Sevilla en $1540^{29}$.

Acorde con la frenética actividad de los artistas, cuatro días después de este acuerdo, Niccolò y Della Porta contrataron los relieves de la puerta del Palacio Salvaggio en la Plaza de San Bernardo de Génova (Fig. 7). Aquí los escultores se comprometían a realizar un modelo de terracota $\mathrm{y}$, posteriormente, un portal $^{30}$. Como resultado, en esta portada sostenida por columnas dóricas y pedestales Niccolò volvió a mostrar su maestría en el uso del schiacciato para plasmar armas y escudos familiares.

Poco después de esta obra, los escultores realizaron un portal para el Reverendo Gregorio Pallavicini, en el que también trabajó Giovannni del Bosso. El encargo consis-

${ }^{26}$ Estella y Lamera, "Niccolò da Corte".

${ }^{27}$ María José Redondo Cantera, “La arquitectura de Carlos V y la intervención de Isabel de Portugal: Palacios y fortalezas", en Carlos $V$ y las artes. Promoción artística y familia imperial, ed. por María José Redondo Cantera y Miguel Ángel Zalama (Valladolid: Universidad de Valladolid, 2000), 101.

${ }^{28}$ Estella, "La importación de esculturas...", 428.

${ }^{29}$ Redondo, “La arquitectura de..., 101.

${ }^{30}$ Earl Rosenthal, The lombard sculptor Niccolò da Corte in Granada from 1537 to 1552 (Joh, Enschedé en Zonen, 1966), 215.

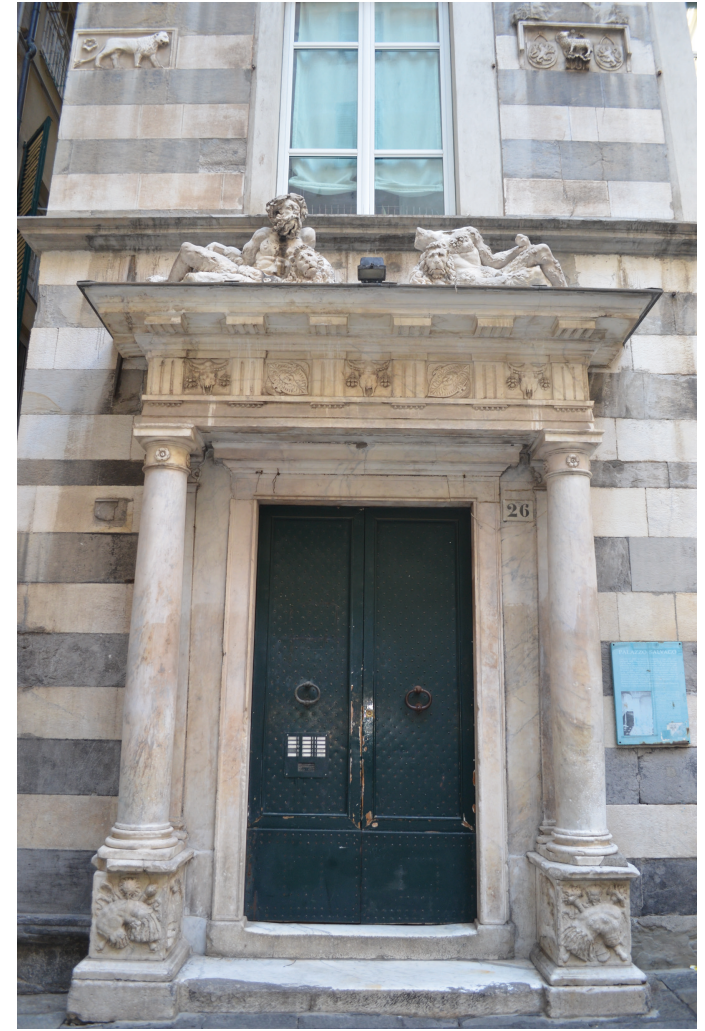

- Fig. 7. Puerta del Palacio de Agostino Salvaggio, plaza San Bernardo. 1532. Génova. Fotografía de la autora.

tía en un "portal com sopra de decoro dell'antico...con grosse colonne e pilastri e capiteli ricamente intagliati", sobre el que se asentarían dos figuras de dos palmos ${ }^{31}$. Más allá de la relevancia del portal, la importancia de esta obra radica en el destinatario: Gregorio Pallavicini, intermediario de la tramitación de dos chimeneas realizadas por Antonio Novo di Lancia y Gio Maria Pasallo en 1533 para el Gran Escudero de Carlos V, Jean Henin Liètard. Según Estella, Pallavicini también pudo actuar como intermediario en la realización dela Fuente de las Tres Gracias realizada entre 1535 y 1537 para el Gran Escudero. Esta fuente estaría compuesta por el grupo de las Tres Gracias, cuatro putti de mármol y una figura de Ceres de tamaño natural, y la "vasca de marmo mischio" encargada por Pallavicini a Da Corte en 15352. Esta fuente

\footnotetext{
${ }^{31}$ Estella, "La importación de esculturas...", 430.

${ }^{32}$ Estella, "La importación de esculturas...", 430.
} 
debió de incrementar la fama de la compañía como escultores de fuentes, puesto que a partir de entonces recibieron numerosos encargos ${ }^{33}$ en la ciudad como la del palacio de Felipe de Roi, (duque de Ascoli) ${ }^{34}$ que consistiría en dos pilas y siete figuras ${ }^{35}$, varias fuentes realizadas para Andrea Doria, o la comisionada por el Senado para la Plaza Nueva en $1536^{36}$. Proyectos, que los escultores debieron combinar con la ejecución del sepulcro del obispo Cybo de la catedral de Génova concluido en 1537, el portal de piedra negra para el palacio de Giacomo Calvi o la estatua de Ansaldo Grimaldi realizada entre $1539-1547^{37}$ para el palacio de San Jorge ${ }^{38}$.

\section{EL CÉNIT DE LA TRAYECTORIA AR- TÍSTICA DE NICCOLÒ DA CORTE}

Según López Torrijos, de regreso tras la victoria de Túnez, Álvaro de Bázán debió decidir la realización de una serie de reformas en sus casas de Granada. Si bien es cierto, que, como indica Estella los grandes escultores de jardines y fuentes solían ser artistas florentinos ${ }^{39}$, hemos visto como, desde los años treinta del siglo XVI, habían

\footnotetext{
${ }^{33}$ Además en 1534 realizaron un Crucifijo en la Confraternidad de genoveses de Santa Brígida. Estella y Lamela, "Niccolò da Corte".

${ }^{34}$ Estella y Lamela, “Niccolò da Corte".

${ }^{35}$ Carrol Brentano, "Giovanni Della Porta", en Dizionario Biografico degli Italiani, vol. 37, 1989, sn. http:// www.treccani.it/enciclopedia/della-porta-giovanni-giacomo_(Dizionario-Biografico)/.
}

\footnotetext{
${ }^{36}$ Hasta tiempos recientes se pensaba que esta fuente era la ubicada en la actual Plaza Marsala de Génova: una pieza de cuatro delfines que se entrelazan y cuyos mascarones expulsan el agua de la taza. Sin embargo, tras el hallazgo de un documento inédito, Di Raimondo ha documentado que esta fuente no corresponde con la realizada por Della Porta y Da Corte, entre otros motivos porque la fuente de la Plaza Nueva sería una fuente "a candelabro". Armando Di Raimondo, "Un inedito documento per la storia della fontana di piazza Marsala", Rivista Acompagna no. 2 (2017).

${ }^{37}$ Brentano, "Giovanni Della Porta".

${ }^{38}$ Estella y Lamela, "Niccolò da Corte".

${ }^{39}$ Estella, “La importación de esculturas...", 425.
}

comenzado a proliferar las obras realizadas por artistas lombardos, Antonio Maria Aprile, Gian Giacomo Della Porta y Niccolò Da Corte, no sólo para la ciudad de Génova, sino para otros países europeos. En este contexto, y teniendo en cuenta las intensas relaciones de Álvaro de Bazán, Capitán General de las Galeras de España y Andrea Doria $^{40}$, se entiende el deseo de encargar a los artistas de la ciudad la renovación de sus casas en Granada, inspirado en los innovadores palacios genoveses, como el de Martín Centurión ${ }^{41}$. A pesar de que no queda rastro de la obra, gracias a los estudios de López Torrijos sabemos que el proyecto consistía en la renovación del patio incorporando una huerta con jardín, en el que se situarían dos fuentes monumentales, y la decoración del interior. Para la reforma del patio el 19 de julio de 1536, Gian Giacomo della Porta y Gian Pietro Passalo fueron contratados para realizar 200 balaustres, 34 piezas para cornisas de distinto tamaño y dos fuentes de mármol similares a las del Palacio Doria en Fassolo. Una labor de gran envergadura y de tiempo limitado que motivó la incorporación el 5 de agosto de Guglielmo della Porta y Niccolò da Corte. Así, a principios del año siguiente, la obra ya estaba concluida y podía ser aposentada antes de la Pascua Resurrección, como estaba previsto. Concluidas las piezas, el 29 de enero y el 14 de febrero de 1537, Niccolò da Corte y Antonio Semini se comprometieron a embarcarse en la nave de Juan Danda para desplazarse a Granada o donde Álvaro de Bazán quisiera, "para trabajar acorde con él" ${ }^{\prime 2}$. Los artistas debieron llegar a Granada entre los meses de marzo y abril: Da Corte se encargaría de aposentar los mármoles en el patio y de colocar las fuentes y Semino de

\footnotetext{
${ }^{40}$ Rosa López Torrijos, "Arte e historia común en el Palacio del Viso" en España y Génova. Obras, artistas y coleccionistas, dir. por Pietro Boccardo, José Luis Colomer y Clario di Fabio (Madrid: Colección Carolina, 2004), 130.

${ }^{41}$ Rosa López Torrijos, “Las casas de la familia Ba-

${ }^{42}$ Torrijos, “Las casas de...”, 29 y 31.
} 29. 
la decoración pictórica ${ }^{43}$. Sin embargo, estas obras no llegaron a realizarse ${ }^{44}$.

Poco después de su llegada a Granada, Niccolò se integró en las obras de las Casas Reales de la Alhambra. Para ello, pudo contactar directamente con Luis Hurtado de Mendoza ${ }^{45}$, pero también, aprovechar su conexión con Julio Aquiles y Alexandre Mayner, artistas que habían trabajado en el Palacio Doria ${ }^{46}$ y que, desde 1534, se encargaban de la ornamentación pictórica de las Estancias Imperiales ${ }^{47}$. Con todo, la mejor muestra de su habilidad fue la realización de la figura de la Fama para la fachada meridional del Palacio de Carlos V. Aunque a su llegada la puerta estaba iniciada ${ }^{48}$, Niccolò introdujo ciertas modificaciones. De esta forma, Rosenthal pudo distinguir su mano en la figura de la derecha, donde se advierte su habilidad para adaptarla a la enjuta o su maestría en el juego de volúmenes en las

\footnotetext{
${ }^{43}$ A pesar de la existencia del contrato y de los intentos por hallar la huella de Semino en la ciudad, la presencia del artista continúa siendo desconocida como se refleja en el último estudio realizado al respecto. David García Cueto, "El pintor genovés Antonio Semino en Granada", en La pintura italiana en Granada. Artistas y coleccionistas, originales y copias, dir. por David García Cueto (Granada: Universidad de Granada, 2019), 123126.

${ }^{44}$ Rosa López Torrijos, “Arte e historia...", 130.

${ }^{45}$ Fernando Marías, “El palacio de Carlos V en Granada: formas romanas, usos castellanos", en Carlos $V y$ las artes: promoción artística y familia imperial, coord. por Miguel Ángel Zalama Rodríguez y María José Redondo Cantera (Valladolid: Junta de Castilla y León. Consejería de Educación y Cultura, 2000), 126.
}

${ }^{46}$ Nuria Martínez Jiménez, "La trayectoria italiana de Julio Aquiles en el círculo de Rafael", Archivo Español de Arte, no 365 (2019), 14.

${ }^{47}$ Martínez Jiménez, "La trayectoria italiana...", 2. Para profundizar sobre la labor de artistas y artesanos en la Alhambra, destacando la figura de Niccolò da Corte, véase: Esther Galera Mendoza, Artistas y artesanos en las obras reales de la Alhambra (Granada: Universidad de Granada, 2019), 291- 297.

${ }^{48}$ Hanno- Walter Kruft y Anthony Roth, "The Della Porta workshop in Genoa", Annali della Scuola Normale Superiore di Pisa. Classe di Lettere e Filosofia, Serie III, vol. 3, no 3 (1973), 911.

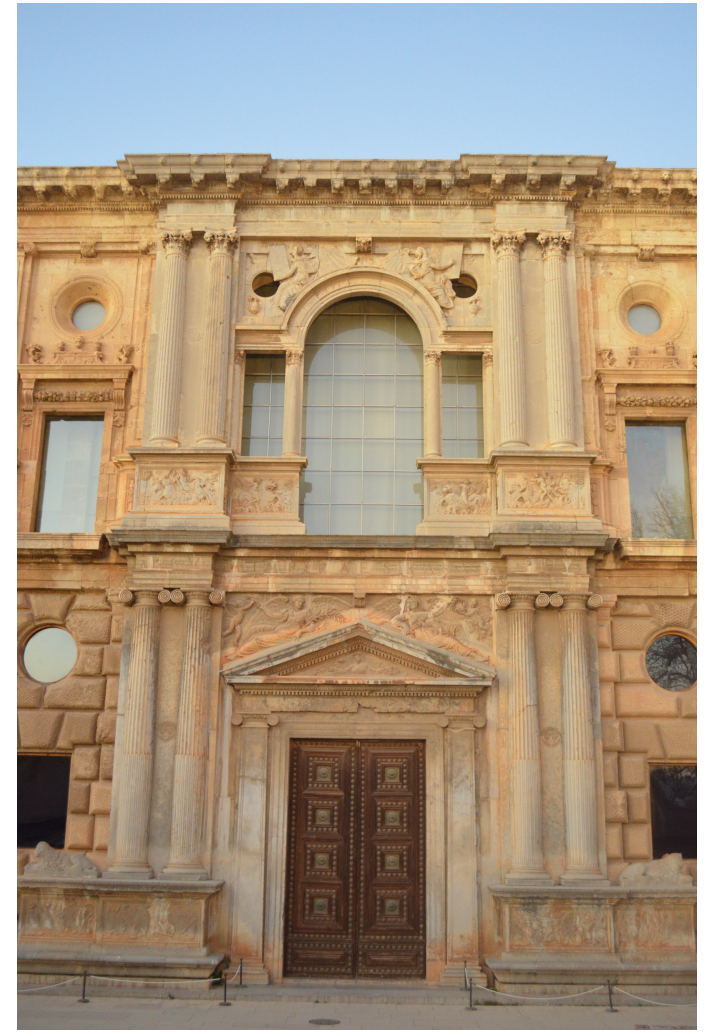

- Fig. 8. Portada del medio día del Palacio de Carlos V. Granada. Fotografía de la autora

alas, el cabello o el ropaje. La figura fue tasada en noviembre de 1537 por Julio Aquiles, Pedro Machuca y Diego de Siloé49 por un valor de 120 ducados $^{50}$ (Fig. 8). Como se aprecia en el alto valor resultante de la tasación, la escultura tuvo una gran acogida, por lo que, aunque en $1538^{51}$ renovó la compañía

${ }^{49}$ Manuel Gómez- Moreno Martínez, "Los pintores Julio y Alejandro y sus obras en la Casa Real de la Alhambra", Boletín del Centro Artístico de Granada, 22 (1887), 206. Earl Rosenthal, El palacio de Carlos V de Granada (Madrid: Alianza, 1988), 273. En su estudio Gómez Moreno propuso que el pintor Nicolao da Génova podría ser Niccolò Da Corte. Sin embargo, a nuestro juicio esta hipótesis no resulta plausible, entre otros motivos, por la gran diferencia salarial entre ambos artistas. Además, recientemente se ha hallado la referencia a un artista llamado Niccolò da Génova que trabajó con Julio Aquiles en Granada. Manuel Gómez Moreno Martínez, “Los pintores Julio...", p, 203. Nuria Martínez Jiménez, "Pintura mural del Renacimiento italiano en la Alhambra" (tesis doctoral, Granada, 2019), 177.

\footnotetext{
${ }^{50}$ Rosenthal, El Palacio de Carlos V..., 283.

${ }^{51}$ Rosenthal, El Palacio de Carlos V..., 73. En 1538 el
} 
genovesa con Della Porta, el artista continuó trabajando en la portada del Palacio, donde entre 1538 y 1539 empleó la técnica de schiacciato para realizar los característicos relieves militares de los pedestales.

Interrumpidas las obras de la puerta meridional, Da Corte volvió a Génova donde continuó trabajando en el Palacio Ducal hasta $1541^{52}$. Este hecho no impidió su participación en el palacio granadino, para el que realizó los diseños de las argollas que se asentaron en enero de $1542^{53}$ (Fig. 9). Este tipo de decoraciones ya había sido empleado en una de las portadas del Palacio Doria y en el Palacio Salvaggio de Génova, por lo que Niccolò pudo enviar los diseños de las piezas que, posteriormente, serían fundidas en bronce en Granada. Como resultado, el Palacio de Carlos V cuenta con cuarenta argollas de bronce en su perímetro. La mayor parte se compone por dos columnillas de capitel jónico, envueltas por una filacteria con el Plus Oultre, y sujetas al muro por cabezas de león. Pero también, es posible distinguir en las esquinas diez argollas sostenidas por cabezas de águilas en las esquinas, de forma amorcillada y unidas por mascarones.

La última obra conocida en Génova es la portada del Palacio de Lanfranco Cicala ${ }^{54}$. Un conjunto arquitectónico reformado en 1542, en el que Gian Giacomo Della Porta y Niccolò Da Corte realizaron una portada con columnas dóricas, que apoyan sobre bases decoradas con frisos de cabezas de león, medusas y trofeos de guerra. En la parte superior, destacan dos sinuosas figuras femeninas colocadas en una cama de cornucopias ricas en flores y frutos, que originariamente sostenían el escudo de la Casa.

taller de Génova se amplió con Nicolò Longhi, Giacomo Carlone, Michele e Battista Solari da Carona, Antonio Novo di Lancia y Giovanni Domenico Solari di Piuma. Stella y Lamela "Niccolò da Corte".

${ }^{52}$ Entre 1533-1541 se registran pagos por sus intervenciones en el Palacio Ducal. Estella y Lamela "Niccolò da Corte".

\footnotetext{
${ }^{53}$ Rosenthal, El Palacio de Carlos V..., 285.

${ }^{54}$ Estella y Lamela, “Niccolò da Corte".
}

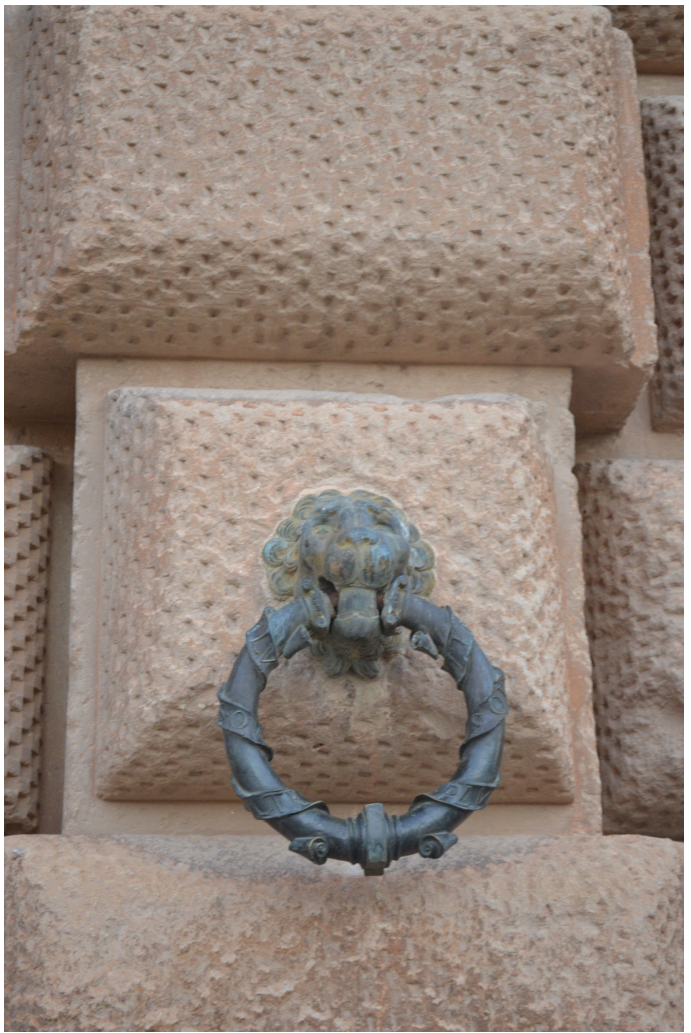

- Fig. 9. Argolla. Tramo bajo de la fachada sur del Palacio de Carlos V. 1540-1542. Granada. Fotografía de la autora.

En este tiempo, Niccolò también trabajó para Fernando Álvarez de Toledo y Pimentel, "el Gran Duque de Alba". La única referencia de esta labor es que en 1540 le había adelantado 400 escudos $^{55}$. A pesar de la relevancia del encargo no conocemos con exactitud la obra realizada. Según Gómez Moreno, el encargo estaría destinado al palacio principal de la casa Álvarez de Toledo en Alba de Tormes (Salamanca), donde pudo identificar algunas piezas ${ }^{56}$. Sin embargo, ante la escasez de noticias sobre este palacio, Estella señaló la posibilidad de que el encargo formara parte del jardín de Sotofermoso, en Abadía (Cáceres) ${ }^{57}$. Una obra de gran envergadura para la que en 1542 el III Duque de Alba encargó numerosos mármoles genove-

\footnotetext{
${ }^{55}$ Estella, “La importación de esculturas...", 433.

${ }^{56}$ Manuel Gómez Moreno, Catálogo Monumental de España. Provincia de Salamanca (1901-1903) (Madrid: Ministerio de Educación y Ciencia, 1967), 368-390.

${ }^{57}$ Estella, “La importación de esculturas...”, 434.
} 


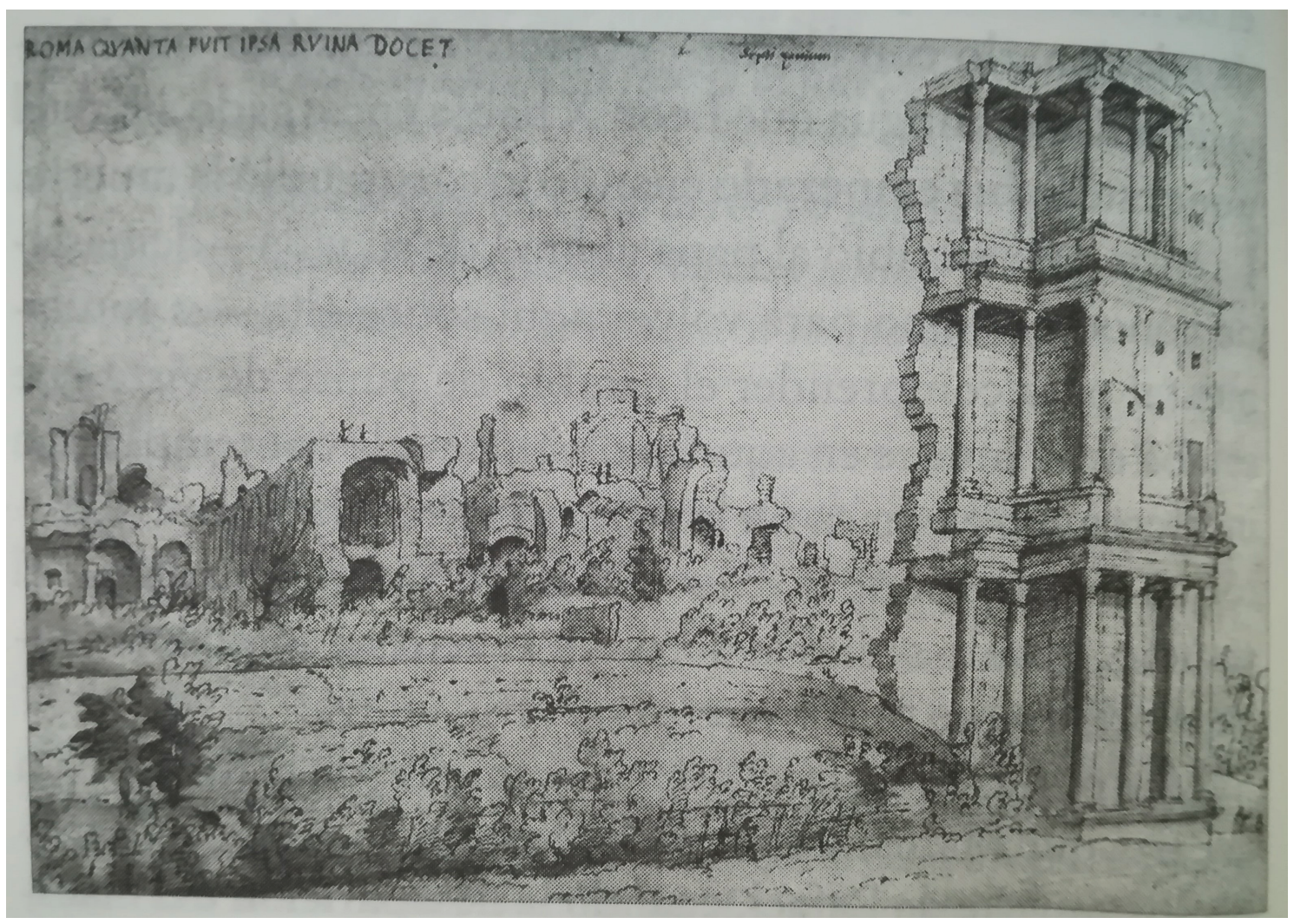

- Fig. 10. Anónimo A. Herman Posthumus, Vista del Palatino y de Septizonium c. 1536. Album atribuido a Marten van Heemskerck II, fol. 87 vo, 85rº. Imagen extraída de Nicole Dacos, «Roma quanta fuit» O la invención del paisaje de ruinas (Barcelona: Acantilado, 2004), 32.

ses y que explicaría la ausencia del artista de Génova en $1543^{58}$.

En torno a 1545, Niccolò volvió a Granada donde intervino en una de sus obras paradigmáticas: el Pilar de Carlos V, anteriormente conocido como el Pilar de las Cornetas. Una de las singularidades de este conjunto es su disposición. Hasta el momento las fuentes señaladas son exentas al muro, una tipología propia de las fuentes florentinas, que como hemos visto había comenzado a proliferar en los jardines de los palacios reales y de la nobleza. Sin embargo, a diferencia de los casos anteriormente mencionados, la fuente granadina se encuentra

${ }^{58}$ De hecho el artista no se encontraba en Génova el 7 de junio de 1543, cuando dio un poder al notario Francesco Pallavicino para que hiciera frente a sus obligaciones en la ciudad. Kruft y Roth, The Della Porta Workshop..., 911. adosada al muro en la vía de acceso a la Alhambra ${ }^{59}$.

A nuestro juicio, la génesis del Pilar se halla en el paso de la comitiva imperial por Roma en 1536. Desde 1530, las fuentes efímeras se habían convertido en una constante en los recibimientos triunfales del emperador. Como indica Ferretti, estas fuentes tenían un fuerte carácter ejemplarizante, que se integraba a la perfección en los ingresos triunfales de los Austrias, puesto que en ellas se encuentran elementos simbólicos y alegorías destinadas a ensalzar la identidad de la ciudad anfitriona (de ahí la presencia de símbolos autóctonos o de mitos fundacionales) y la de los propios monarcas, asocia-

\footnotetext{
${ }^{59}$ Sobre la remodelación de los jardines de la Alhambra en época moderna léase: Esther Galera Mendoza, "Los jardines de la Alhambra durante el reinado de los Austrias", Goya, no 333 (2010), 288-307.
} 


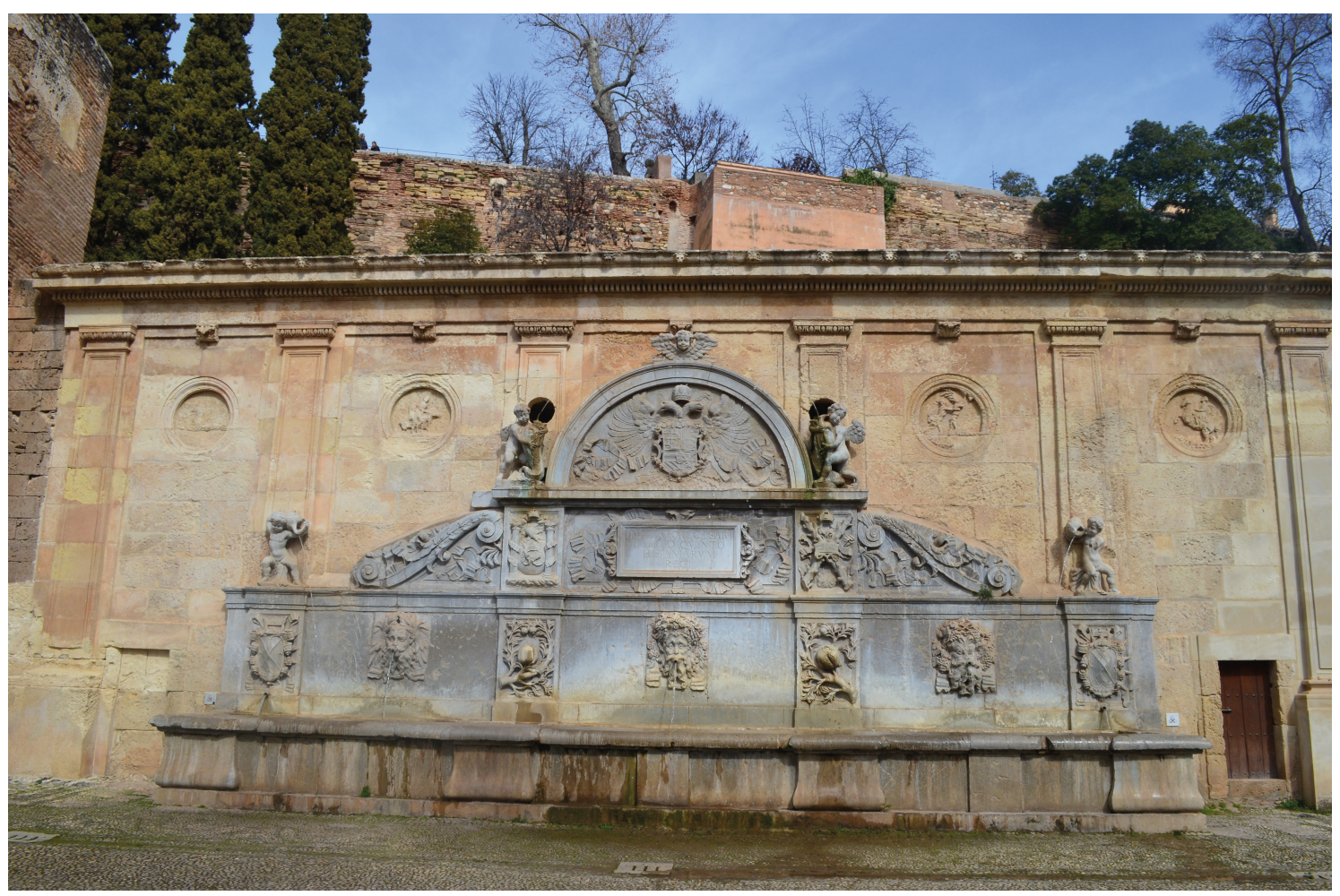

- Fig. 11. Pilar de Carlos V. 1545-1548. Granada. Fotografía de la autora.

dos a la mitología grecorromana ${ }^{60}$. La obra cumbre en este tipo de decoraciones fue la reforma del Settizonio para el paso de la comitiva imperial por Roma en abril de 1536. Dentro del complejo programa ornamental ideado por Sangallo para recibir al emperador, se encontraba el paso frente al antiguo Settizonio, una construcción romana localizada en la esquina suroeste del Palatino, que había sido muy admirada por los artistas del Renacimiento (Fig. 10). Partiendo de los restos de su fachada pantalla, a modo de los antiguos teatros romanos, el poeta y erudito Giovenale Mannetti, el eclesiástico Niccolò Gaddi, el arquitecto Antonio da Sangallo y, posiblemente, Baldasarre Peruzzi ${ }^{61}$, consiguieron establecer un complejo entramado de máquinas para hacer brotar "acqua rossa", un líquido perfumado que, en la Antigüedad, bañaba los estanques. Tras el paso

${ }^{60}$ Emanuela Ferreti, "All'origine de una nuova espressività dell'acqua nel contesto urbano: Il Settizonio nel Trionfo di Carlo V a Roma (1536)", Annali della Scuola Normale Superiore di Pisa, nº 5 (2019), 181-183.

${ }^{61}$ Ferreti "All'origine de...", 194. de la comitiva imperial, algunas de estas fuentes (concebidas como estructuras efímeras) pasaban a formar parte de la "Ciudad Nueva", una urbe en la que el agua, no sólo constituía un elemento vital, sino que su ornato se vinculaba a la Roma clásica. De esta forma, se fue creando una nueva significación de la fuente urbana ligada a la "idea de un espacio teatralizado, como epítome de la nueva ciudad"62.

A pesar de la hipótesis propuesta por Marías, resulta difícil pensar que Machuca acompañara a Luis Hurtado de Mendoza a Túnez ${ }^{63}$ o que viera los fastos preparados para el paso de la comitiva. Pero sí es posible que recibieran noticias de otras personalidades que presenciaron los actos, como Francisco de los Cobos, Álvaro de Bazán, el Duque de Alba e incluso de Diego Hurtado

\footnotetext{
${ }^{62}$ Ferreti "All'origine de...", 184.

${ }^{63}$ Marías, “El palacio de...", 126. Además, como señaló Redondo en octubre de 1535 el Conde de Tendilla ya se encontraba en Granada, por lo que no pudo asistir a los fastos. Redondo, "La arquitectura de...", 81
} 
de Mendoza (tío de Iñigo Hurtado de Mendoza, Alcaide de la Alhambra desde 1539) a quien Gómez Moreno atribuye el la concepción erudita de las composiciones mitológicas del pilar ${ }^{64}$.

En este contexto, y teniendo en cuenta la relevancia del Palacio de Carlos V, pensamos que el Conde y Machuca decidieron incorporar un pilar formando parte del itinerario triunfal iniciado en la Puerta de las Granadas (1536). De esta forma, igual que en Roma, a lo largo del recorrido, la comitiva atravesaría imponentes arcos y podría pararse ante una fuente monumental, que no sólo servía de abrevadero para los caballos, sino que presentaba un potente mensaje simbólico. Además, la fuente serviría como muro de contención de una nueva plaza ubicada delante de la Puerta de la Justicia (Fig. 11). Para crear este potente entramado Machuca debió idear una compleja maquinaria hidráulica compuesta por tuberías ${ }^{65}$, que recogieran el agua procedente de la acequiar real, y concebir una imponente fachada pantalla acorde con los modelos de la Antigüedad. Para ello, pudo servirse de las referencias bibliográficas, pero también de su propia experiencia, puesto que durante su estancia en Roma pudo admirar las ruinas de la Villa Adriana o el propio Settizonio, así como el proyecto para la Villa Madama de Rafael, en el que se contemplaba la realización de una especie de ninfeo con una fuente ${ }^{66}$.

Concluido el diseño de Pedro Machuca, en octubre de $1545^{67}$ se llamó a Niccolò Da Corte, que ya contaba con una sólida experiencia en la realización de jardines y fuentes, como la del Palacio Doria o la del Gran Escudero. Aunque las trazas del maestro

${ }^{64}$ Manuel Gómez- Moreno Martínez y Agustín Bustamante García. Las águilas del Renacimiento español. Bartolomé Ordóñez, Diego Silóe, Pedro Machuca, Alonso Berruguete (Madrid : Xarait, 1983), 117.

${ }^{65}$ Luis Cervera Vera, La fábrica y ornamentación del Pilar de Carlos V en la Alhambra granadina (Granada: Patronato de la Alhambra y Generalife, 1987), 19.

${ }^{66}$ Ferreti, "All'origine de...", 194.

${ }^{67}$ Rosenthal, El Palacio de Carlos V..., 82.

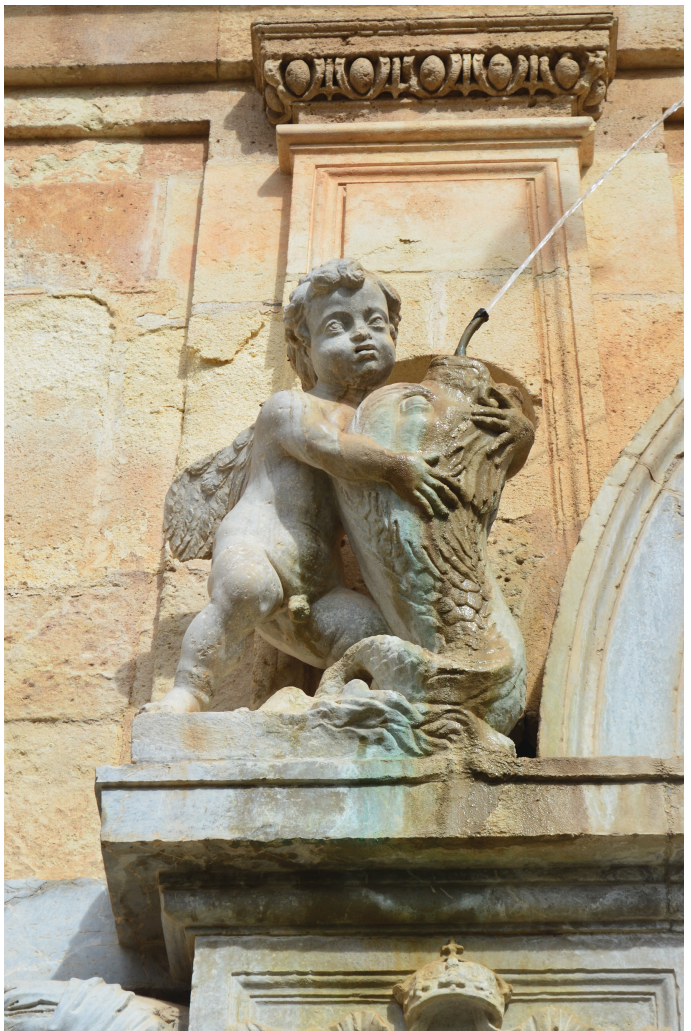

- Fig. 12. Niccolò da Corte, Angelote sosteniendo un delfín. Pilar Carlos V. 1545-1548. Granada. Fotografía de la autora.

eran bastante precisas, como señaló Rosenthal, Niccolò introdujo ciertas modificaciones en la traza para acomodar las figuras, $y$ también, en el ornato donde se aprecian ecos de sus obras anteriores ${ }^{68}$. Es el caso de las cintas, ya empleadas en la sala de los Vientos del Palacio Doria, cuyo sutil relieve remite al tratamiento de las alas de las victorias de la puerta de acceso al palacio de Génova o de la puerta meridional del Palacio de Carlos V. No obstante, los motivos más destacados son los cuatro putti sosteniendo conchas y delfines que recuerdan a los empleados por Niccolò en el Palacio Doria, en la plaza de San Mateo (donde también se incluye una cartela con una inscripción) y, sobre todo, a los de la fuente de los Delfines del Palacio de Fassolo. También sería el encargado de incluir los roleos, decoraciones que no encajan con el trazado arquitectónico, pero sí con el conjunto en general. Como resultado,

\footnotetext{
${ }^{68}$ Rosenthal, El Palacio de Carlos V..., 84.
} 
se creó una imponente fachada de arenisca compuesta por un muro frontal, coronado por una cornisa corrida y dividido por seis pilastras dóricas. En los vanos encontramos tondos con escenas mitológicas: Hércules matando a la Hidra, Los hermanos Frixo y Hele sobre el velloncino, Dafne perseguida por Apolo y Alejandro Magno sobre el búfalo.

Sobre este paño se colocó una estructura marmórea de tres cuerpos superpuestos que se van ensanchando hacia la base. En la parte superior se halla un frontón curvo con las armas de Carlos V, flanqueado por dos putti que sostienen delfines y coronado por un querubín. En la parte central del segundo cuerpo se halla la cartela con la inscripción: IMPERATORI CAESARI KAROLO QVINTO HISPANIARVM REGI ubicada entre dos plintos: uno de ellos presenta el emblema del Plus Ultra; el otro, las aspas de la casa Borgoña. En los extremos se despliegan los dos roleos.

Bajo este cuerpo se extiende el tercero, dividido verticalmente por cuatro pedestales que dan lugar a tres vanos horizontales. En los pedestales se apoyan dos putti sosteniendo caracolas y campean las armas del II Conde de Tendilla (Fig. 12). En el centro, luce el emblema de Granada y en los vanos aparecen potentes mascarones ${ }^{69}$ que surten a la fuente de agua y que representarían las estaciones o los tres ríos de la ciudad: Genil, Beiro y Darro ${ }^{70}$. Finalmente indicar la elegancia de los perfiles de la pila oblonga de la fuente, que según Rosenthal serían incluidos por Niccolò ${ }^{71}$. Como resultado, acorde con la sentencia de Ferreti: "gracias a la interacción de la materia, el arte, la arquitectura y el conocimiento constructivo, el vitalismo del

\footnotetext{
${ }^{69}$ Como es sabido, los emblemas, los mascarones y la cabeza de uno de los angelotes fueron rehechos por Alonso de Mena en 1624, igual que los medallones que, a pesar de las restauraciones, continúan estando muy desgastados. Rosenthal, El Palacio de Carlos V..., 83-84. Cervera, La fábrica y..., 56.
}

${ }^{70}$ Rosenthal, El Palacio de Carlos V..., 70.

${ }^{71}$ Rosenthal, El Palacio de Carlos V..., 84. agua se realza figurativamente en el plasticismo articulado de las fuentes: se reúnen, con especial énfasis, aquellos personajes de energía, dinamismo, maravilla, estupor, placer estético y virtuosismo técnico que connotan el proyecto del Triunfo y, en general, del episodio festivo en el Renacimiento maduro"72.

Entre 1548 y 1551 Niccolò realizó su última obra ${ }^{73}$ : la ventana y los relieves con las historias de Neptuno de la fachada meridional. La ventana estaba proyectada desde 1537, sin embargo, posteriormente se alteró. Para ello, Machuca volvió a contar con Niccolò, aunque el artista no llegó a culminar la obra por el retraso en la llegada de la piedra. Si tuvo tiempo de realizar las dos figuras femeninas, entre las que Rosenthal identificó a la Historia ${ }^{74}$ y gran parte de los relieves con escenas marítimas que aludirían a la victoria naval en Túnez ${ }^{75}$. Si bien es cierto, que el tema de Neptuno era conocido por Niccolò, en esta ocasión planteó unas composiciones de radiante novedad técnica e iconográfica, sobre todo, en la figuración de la Boda de Neptuno y Anfítrite. Para representar a Neptuno calmando la tempestad, partió por un modelo empleado anteriormente por Giulio Romano o Perino del Vaga (rápidamente difundido sobre todo a raíz de los grabados de Marcantonio Raimondi), pero presentando a la divinidad en sentada en el carro sosteniendo a los caballos encabritados, composición que remite a uno de los estucos de la sala de los Gigantes del Palacio Doria.

\section{CONCLUSIONES}

Tras analizar la trayectoria de Niccolò da Corte, se advierte la relevancia del artis-

\footnotetext{
${ }^{72}$ Ferreti, “All'origine de...", 179.

${ }^{73}$ Como recogió Rosenthal, durante la realización de estas obras, Niccolò debió enfermar por lo que en junio de 1551. Desde entonces, se refugiaría en la casa de algún comerciante genovés, hasta su muerte en enero de 1552. Rosenthal, El Palacio de Carlos V..., 86.

${ }^{74}$ Rosenthal, El Palacio de Carlos V..., 88.

${ }^{75}$ Rosenthal, El Palacio de Carlos V..., 89.
} 
ta lombardo como escultor de portadas en Génova y en Granada, pero también como escultor de fuentes, identificativo que trascendió su muerte ${ }^{76}$, evidenciando su contribución a la transformación de jardines y palacios en Italia y en España. Entre ellas, sin duda, destacó el Pilar de Carlos V, un conjunto único ubicado en el interior del recinto de la Alhambra, cuyo influjo traspasó la Puerta de las Granadas, para inundar la ciudad de fuentes, como la Fuente Nueva (c. 1556) y, sobre todo, de pilares, como el pilar del Toro (1555-155977), que aún hoy enriquecen la ciudad y surten a sus habitantes del agua procedente de sus ríos.

\section{BIBLIOGRAFÍA}

Águila García, Lucía. La arquitectura del agua: fuentes y pilares de la Edad Moderna en Granada. Granada: Universidad de Granada, 2003.

Alizeri, Federico. Notizie dei professori del disegno in Liguria dalle origini al sec. XVI, V. Genova: Luigi Sambolino tip., 1877.

Baldassarre Ernesto y Bruno Renato. Schedario degli uomini illustri in Savona. Savona: A Campanassa, 1981.

Brentano, Carrol. "Giovanni Della Porta". En Dizionario Biografico degli Italiani, vol. 37, 1989, sn. http://www.treccani.it/enciclopedia/della-porta-giovanni-giacomo_ (Dizionario-Biografico)/.

${ }^{76}$ La última referencia existente sobre el artista es un documento fechado el 5 de marzo de 1554 que se conservaba en el Archivo de Protocolos Notariales de Granada. Se trata de un poder otorgado por Domenico da Corte, vasallo de su Majestad y vecino del Ducado de Milán, en nombre de sus hermanos y herederos de "Niccolò da Corte escultor de fuentes", a Gerónimo de Pergo, milanés, y Alexandro de Casanmaxor, para intervenir en su nombre en los asuntos judiciales que pudieran acontecerse Poder de Domenico da Corte. Archivo del Instituto Gómez Moreno de la Fundación Rodríguez Acosta (AIGM), leg. 44, f. 26r. A pesar de las búsquedas, no hemos podido localizar el documento en el Archivo de Protocolos Notariales de Granada.

${ }^{77}$ Lucía Águila García, La arquitectura del agua: fuentes y pilares de la Edad Moderna en Granada (Granada: Universidad de Granada, 2003), 42.
Boccardo, Pietro. Andrea Doria e le arti. Roma: Palombi, 1989.

Calderari, Lara. "Le trasformazioni tra Quattro e Cinquecento. Necessità manutentive e ambizioni identitarie". Arte e cultura, no $6 / 7$ (2017), 104-129.

Campigli, Marco. "Girolamo da Treviso, Perin del Vaga, Pordenone e Beccafumi. Quatro artista per un ciclo di affreschi genovese". Nuovi Studi, Rivista di arte antica e moderna, $\mathrm{n}^{\circ} 17$ (2011), 37-50.

Campigli, Marco. "Silvio Cosini, Niccolò da Corte e la scultura a Palazzo Doria". Nuovi Studi, Rivista di arte antia e moderna, $\mathrm{n}^{-}$ 20 (2014), 83-105.

Carpeggiani, Paolo y Chiara Tellini. Giulio Romano a Mantova. Mantova: Sintesi, 1987.

Cervera Vera, Luis. La fábrica y ornamentación del Pilar de Carlos V en la Alhambra granadina. Granada: Patronato de la Alhambra y Generalife, 1987.

Dacos, Nicole. «Roma quanta fuit» O la invención del paisaje de ruinas. Barcelona: Acantilado, 2004.

Di Raimondo. Armando. “Un inedito documento per la storia della fontana di piazza Marsala". Rivista Acompagna, no. 2 (2017), s. p.

Estella Margarita y Federica Lamera. Niccolò da Corte. Dizionario Biografico degli Italiani. Volume 31. 1985. http://www.treccani.it/enciclopedia/niccolo-da-corte_\%28Dizionario-Biografico\%29/.

Estella Margarita y Federica Lamera. "La importación de esculturas italianas. Obras en España del taller de los Della Porta, de Giambologna y del Naccherio". En El modelo italiano en las artes plásticas de la Península Ibérica durante el Renacimiento, coordinado por María José Redondo Cantera, 423-454. Valladolid: Universidad de Valladolid, 2004.

Falcón Márquez, Teodoro. “Tipologías constructivas de los palacios sevillanos del 
siglo XVI". En Actas del Tercer Congreso Nacional de Historia de la Construcción, Juan de Herrera, editado por A. Graciani, S. Huerta, E. Rabasa. M. Tabales, 279-284. Madrid: Instituto Juan de Herrera, CEHOPU, Universidad de Sevilla, 2000.

Ferrari, Daniela. Giulio Romano. Repertorio di fonti documentarie. Mantova: Ministero per i beniculturali e ambientali-Ufficio centrale per i beni archivistici, 1992.

Ferreti, Emanuela. "All' origine de una nuova espressività dell'acqua nel contesto urbano: Il Settizonio nel Trionfo di Carlo V a Roma (1536)". Annali della Scuola Normale Superiore di Pisa, no 5 (2019), 179-198.

Galera Mendoza, Esther. Artistas y artesanos en las obras reales de la Alhambra. Granada: Universidad de Granada, 2019.

Galera Mendoza, Esther. "Los jardines de la Alhambra durante el reinado de los Austrias", Goya, no 333 (2010), 288-307.

García Cueto, David. “Aproximación al mecenazgo de la comunidad genovesa en el Reino de Granada durante los siglos XVI y XVII". En Génova y la Monarquía Hispánica (1528-1713), coordinado por Manuel Herrero Sánchez, Yasmina Rocío Ben Yessef Garfia Carlo Bitossi y Dino Puncuh, 705-730. Génova: Società Ligure di Storia Patria, 2011.

García Cueto, David. "El pintor genovés Antonio Semino en Granada". En La pintura italiana en Granada. Artistas y coleccionistas, originales y copias, dirigido por David García Cueto, 123-126. Granada: Universidad de Granada, 2019.

Girón Pascual, Rafael María. “Las Indias de Génova Mercaderes genoveses en el reino de Granada durante la edad moderna (ss. XVI-XVIII)"'. Tesis doctoral. Granada, 2012.

Gómez Moreno, Manuel. Catálogo Monumental de España. Provincia de Salamanca (19011903). Madrid: Ministerio de Educación y Ciencia, 1967.
Gómez Moreno, Manuel. Guía de Granada, tomo I. Granada: Universidad de Granada, 1998.

Gómez Moreno, Manuel y Agustín Bustamante García. Las águilas del Renacimiento español: Bartolomé Ordóñez, Diego Siloe, Pedro Machuca, Alonso Berruguete. Madrid: Xarait, 1983.

Helfer, Yasmine. “Gugliermodella Porta dalDuomo di Genova al Duomo di Milano". Prospettiva. Rivista di storiadell'arteantica e moderna, $\mathrm{n}^{-} 132$ (2008), 61-77.

Kruft Hanno, Walter y Anthony Roth. "The Della Porta workshop in Genoa". Annali della Scuola Normale Superiore di Pisa. Classe di Lettere e Filosofia, serie III, vol. 3, no 3 (1973), 893-954.

López Torrijos, Rosa. “Arte e historia común en el Palacio del Viso". En España y Génova. Obras, artistas y coleccionistas, dirigido por Pietro Boccardo, José Luis Colomer y Clario di Fabio, 129-138. Madrid: Colección Carolina, 2004.

López Torrijos, Rosa. "Las casas de la familia Bazán en Granada". Archivo Español de Arte, no 313 (2006), 23-42.

Marías, Fernando. "El palacio de Carlos V en Granada: formas romanas, usos castellanos". En Carlos V y las artes: promoción artística y familia imperial, coordinado por Miguel Ángel Zalama Rodríguez y María José Redondo Cantera, 107-128. Valladolid: Junta de Castilla y León, Consejería de Educación y cultura, 2000.

Martínez Jiménez, Nuria. "La trayectoria italiana de Julio Aquiles en el círculo de Rafael". Archivo Español de Arte, no 365 (2019), pp. 1-16.

Martínez Jiménez, Nuria. “Pintura mural del Renacimiento italiano en la Alhambra". Tesis doctoral. Granada, 2019.

Parma Armani, Elena. Il secolo d'oro dei genovesi: il Cinquecento, en La scultura a Genova e in Liguria dalle origini al cinquecento. Génova: Cassa di Risparmio di Genova e Imperia, 1987. 
Redondo Cantera, María José. "La arquitectura de Carlos V y la intervención de Isabel de Portugal: Palacios y fortalezas". En Carlos $V$ y las artes. Promoción artística y familia imperial, editado por María José Redondo Cantera, y Miguel Ángel Zalama, 67-106. Valladolid: Universidad de Valladolid, 2000.

Romano, Giulio. Cronaca del Soggiorno di Carlo V in Italia (dal 26 Luglio 1529 al 25 Aprile 1530). Documento di Storia Italiana estratto da un códice della Regia Biblioteca Universitaria di Pavia. Milán: Ulrico Hoepli, 1893.

Rosenthal, Earl. The lombard sculptor Niccolò da Corte in Granada from 1537 to 1552. Joh, Enschedé en Zonen, 1966.
Rosenthal, Earl. Niccolò da Corte and the portal of the palace of Andrea Doria in Genoa. Berlin: Walter de Gruyter \& co, 1968.

Rosenthal, Earl. El Palacio de Carlos V de Granada. Madrid: Alianza, 1988.

Schulz, Markham. Giammaria Mosca Calle Padovano, A Renaissance Sculptor in Italy and Poland. Pensylvania: Pensylvania State Universiti Press, 1998.

Signorini, Rodolfo. Il palazzo del Te e La camera di Psiche. Miti e altre fantasie e storieantichenella villa di Federico II Gonzaga ideata da Giulio Romano a Mantova. Mantova: Sometti, 2001.

Vasari, Giorgio. Le vite dei più eccellenti pittori, scultori e architett. Roma: Newton Comton, 2012. 